\title{
DEFORESTACIÓN, VIOLENCIA Y RETERRITORIALIZACIÓN EN EL NOROESTE DE LA AMAZONIA COLOMBIANA
}

\section{DESMATAMENTO, VIOLÊNCIA E RETERRITORIALIZAÇÃO NO NOROESTE DA AMAZÔNIA COLOMBIANA}

\author{
César Augusto Otálvaro-Sierra \\ Doctorando PPGeo \\ Universidade Federal de Uberlândia, Instituto de Geografia, Uberlândia, MG, Brasil \\ Becario OEA-CAPES \\ Integrante del grupo Recursos Estratégicos, Región y Dinámicas Socioambientales-RERDSA, Instituto de \\ Estudios Regionales-INER, Universidad de Antioquia, Colombia \\ caotalvaros@gmail.com
}

\section{Resumen}

Desde el año 2016, después de las negociaciones de paz entre el Estado colombiano y las Fuerzas Armadas Revolucionarias de Colombia-FARC, en este país se viene presentando un aumento de la deforestación, concentrado en el noroeste de su región Amazónica, en donde las dinámicas territoriales han tenido una fuerte influencia y control por parte de las FARC, y que se ha configurado como una frontera de colonización de la amazonia colombiana. Dicho fenómeno ha producido gran atención y preocupación pública, dadas sus implicaciones ambientales, sin analizar suficientemente sus causas y consecuencias sociales, las cuales permiten comprender un conflicto con profundas raíces en la historia reciente del conflicto armado de esta nación, y con evidentes conexiones con poderes políticos y económicos, que intentan imponer una proyección y un manejo particular del espacio y la sociedad, haciendo que todo este fenómeno alcance una dimensión territorial más compleja. Este artículo tiene por objetivo argumentar cómo ese proceso de transformación responde a una lógica de reterritorialización del espacio, que procura establecer una hegemonía para articularlo a las dinámicas económicas de la nación y, por esta vía, alcanzar su control político.

Palabras clave: Territorio. Deforestación. Violencia. Campesinos. Amazonia.

\section{Resumo}

Desde o ano 2016, após as negociações de paz entre o Estado colombiano e as Forças Armadas Revolucionárias da Colômbia - FARC, neste país vem apresentando-se um aumento do desmatamento, concentrado principalmente no Noroeste da sua região amazônica, onde as dinâmicas territoriais tem tido uma forte influência e controle por parte das FARC, configurando-se uma fronteira de colonização da Amazônia colombiana. Tal fenômeno tem produzido grande atenção e preocupação pública, tendo em vista suas implicações ambientais. Porém, não tem-se analisado suficientemente suas causas e consequências sociais, as quais permitem compreender um conflito com profundas raízes na história recente do conflito político armado desta nação, e com evidentes conexões 
com os poderes políticos e econômicos, que tentam impor uma projeção e uma gestão particular do espaço e da sociedade, fazendo com que todo o fenômeno atinja uma dimensão territorial mais complexa. Este artigo tem por objetivo argumentar como esse processo de transformação responde a uma lógica de reterritorialização do espaço, que tenta estabelecer uma hegemonia para o articular as dinâmicas econômicas da nação, e por essa via, atingir seu controle político.

Palavras-chave: Territorio. Desmatamento. Violência. Camponeses. Amazônia.

\section{Introducción}

Este artículo tiene la intención de ser una exploración y análisis preliminar de las transformaciones territoriales que vienen aconteciendo en el noroeste de la amazonia colombiana, como resultado de las múltiples transformaciones ocurridas a partir de los acuerdos de paz entre la guerrilla de las FARC y el Estado colombiano en 2016. En los dos últimos años la intensificación de la deforestación en esta parte de la Amazonia, ha sido una expresión de dichas transformaciones.

Por lo tanto, el objetivo es argumentar cómo ese proceso de transformación responde a una lógica de reterritorialización del espacio, con la intención de establecer una hegemonía territorial que permita articularlo a las dinámicas económicas predominantes del capital en la nación y, por esta vía, alcanzar su control político. Para esto se están usando la acumulación de tierras y su especulación, como estrategias por parte de actores privados, con la anuencia implícita y explícita del Estado en sus diferentes niveles territoriales, intentando crear un espacio atractivo al capital vinculado al negocio agropecuario, siendo este el fin y la herramienta fundamentales del control ya mencionado.

¿Cuáles son las características de este proceso y como puede ser explicado a partir de su contexto geográfico (espacial e histórico)? ¿Cuáles son los actores y sus intereses, imbricados en dicho proceso? ¿Qué sucede con las poblaciones campesinas que hacen parte de esos territorios? Éstas son las principales preguntas que, si bien no pueden ser solucionadas totalmente en este texto, sí pueden marcar una vía de reflexión y comprensión a partir de un enfoque territorial de la cuestión.

Metodológicamente, el artículo es producto de una revisión de diversas fuentes secundarias (informes oficiales y de ONGs, artículos académicos, prensa, publicaciones de entrevistas con expertos, producción cartográfica y producción teórica) que, por medio 
de una lectura cruzada y comparativa, permitieron realizar una identificación preliminar de los principales factores que impulsan las transformaciones territoriales ya mencionadas, marcando posibles elementos de cuestionamiento para futuros trabajos sobre el tema.

Los conceptos de espacio y territorio configuraron las dos principales herramientas interpretativas de este ejercicio; el primero, a partir del trabajo del trabajo desarrollado por Milton Santos (2002), es comprendido como una potencialidad (más que algo concreto) resultante de la relación entre objetos y acciones, organizados(as) y accionados según lógicas específicas, a veces paralelas, divergentes o contradictorias, pero que en todo caso buscan coherencia entre sí, ya que en el encuentro a través del espacio que crean, dichos objetos y acciones se comportan como sistemas, es decir, que existen en tanto no están aislados y se determinan mutuamente.

Tanto los sistemas de objetos como los de acciones surgen o se implementan en contextos socio-espaciales preexistentes, no actúan en el vacío sino que entran en relación con otros sistemas y configuraciones del espacio, donde entablan relaciones de influencia reciproca; componen una respuesta multivariada, que hace que éste se comporte como una síntesis del tiempo, donde confluyen todos los procesos y sistemas intervinientes en el movimiento configurador. Objetos y acciones, se localizan así, en el movimiento e impulso cultural que reinterpreta y articula sus producciones (acciones y respuestas) en el espacio, en el cual se contextualizan históricamente, definiendo sus rasgos y funciones. Esta potencialidad del espacio se concretiza a partir de su apropiación.

El territorio, como apropiación de una porción delimitada del espacio, es considerado por Raffestin (1993) como la producción de un actor sintagmático (Raffestin, 1993, p. 143), quien proyecta un programa (objetivos e intenciones) en él, tornándole legible dentro de un sistema simbólico. Es, por tanto, una producción (transformación) comunicacional del espacio, que permite relacionarse a los actores involucrados, en procura de satisfacer sus necesidades e deseos.

Dicha apropiación simbólica y configuración de la materialidad es, antes que nada, un ejercicio de poder, ya que concentra las posibilidades de relación que tienen los actores sociales y la sociedad misma, para intercambiar energía e información, acciones que son mediadas por la realidad material y simbólica de la sociedad. La creación e configuración de los territorios equivale, por lo tanto, a la configuración espacial de las 
relaciones de poder, a aquello que puede y no puede ser hecho con el espacio, desde la atribución de los significados que sustentan las acciones, hasta las acciones mismas, ambas pertenecientes a un mismo movimiento de codeterminación que configura y reconfigura constantemente el territorio.

Éste es, siguiendo a Saquet (2015), producto y condición de la relación sociedadnaturaleza, una trama relacional indisociable que permite la reproducción de ambas, en el entendido que la primera hace parte de la segunda, la cual, por su parte, es modificada en dicha relación, además de ser la fuente fundamental de energía para la existencia humana. Esa dinámica responde al movimiento de concretización de las relaciones sociales que son su fuerza creadora (territorialidades: relaciones sociales mediadas por el territorio), las cuales siempre están ocurriendo y reconfigurándose, reorganizando así el territorio como una trama (in)material de relaciones que nunca para de mutar.

Esta propuesta de aproximación (in)material del territorio se mostró útil para la lectura territorial del fenómeno objeto de este artículo, ya que, más allá de su origen relacional y su naturaleza reconfiguradora, rescata la lectura del poder como una de las dinámicas definidoras de éste; además, expone una importante potencia con su consideración sobre la relación de origen con la naturaleza, lo cual permite trasegar caminos de comprensión sobre la relación dialéctica de estos procesos, fundamentales en la reflexión actual sobre la cuestión ambiental.

\section{La cuestión de la deforestación y su localización en la amazonia colombiana}

Desde 2016 (ver gráfico 1) el noroeste de la amazonia colombiana viene presentando un drástico aumento en los procesos de deforestación asociados, fundamentalmente, a la creación de pastizales y a la expansión de la cría de ganado (IDEAM; Ministerio de Ambiente; Gobierno de Colombia, 2017), siendo ésta una práctica de baja tecnología y baja intensidad, la cual requiere de grandes espacios, mismos que son adaptados por medio del corte y la quema de la cobertura vegetal. 
Gráfico 1: Hectáreas deforestadas Región Amazonas Colombia 2016-2019

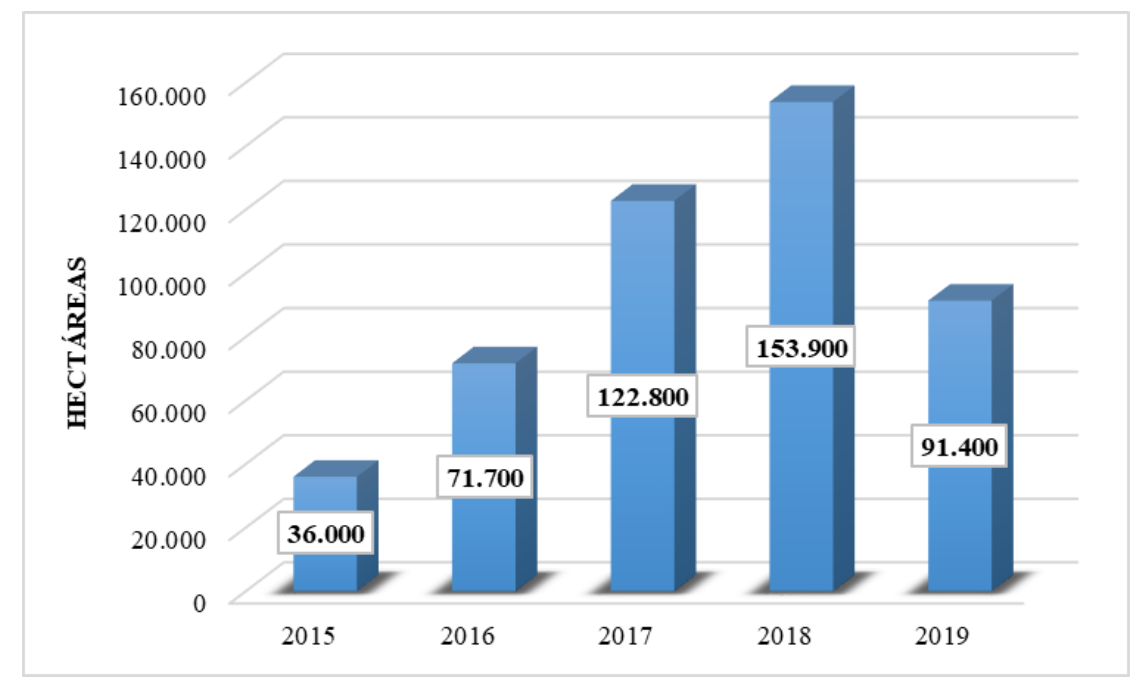

Fuente: Gráfico realizado a partir de Finer M. (2020).

Org.: César Augusto Otálvaro-Sierra, 2020.

Este proceso de deforestación tiene su mayor expresión en los municipios que configuran el límite entre las regiones Andina, Orinoquense e Amazónica del país, una gran área caracterizada por su biodiversidad y localización estratégica, ya que configura un espacio de intercambio biológico, además de ser una puerta de entrada a la amazonia colombiana, parte de una zona que configura un corredor que va hasta la frontera con el Ecuador, tal como puede apreciarse en las figuras 1 y 2 .

Figura 1: Concentración de la deforestación en los límites de las regiones Andina, Orinoquense e Amazónica de Colombia

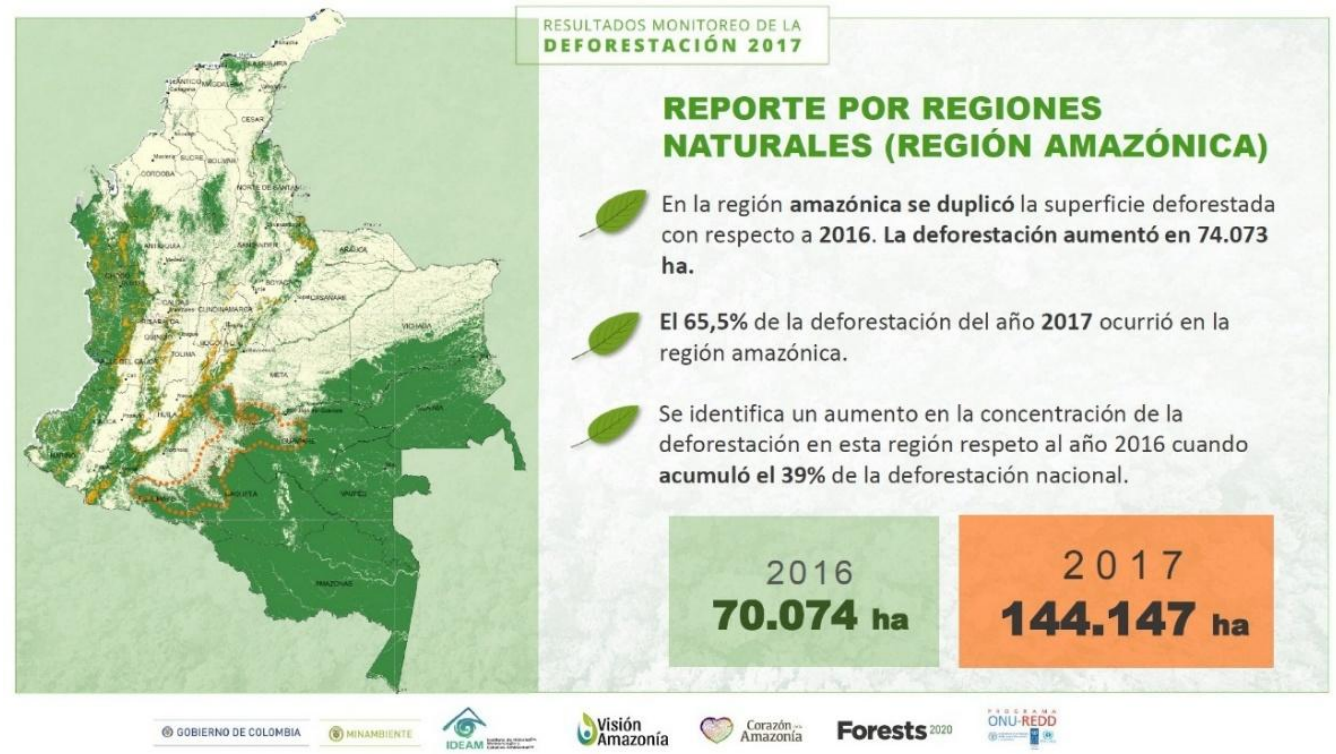

Fuente: Instituto de Hidrología, Meteorología y Estudios Ambientales IDEAM; Ministerio de Ambiente; Gobierno de Colombia, 2017. 
Figura 2: Tendencia histórica municipios con mayor concentración de deforestación ${ }^{1}$

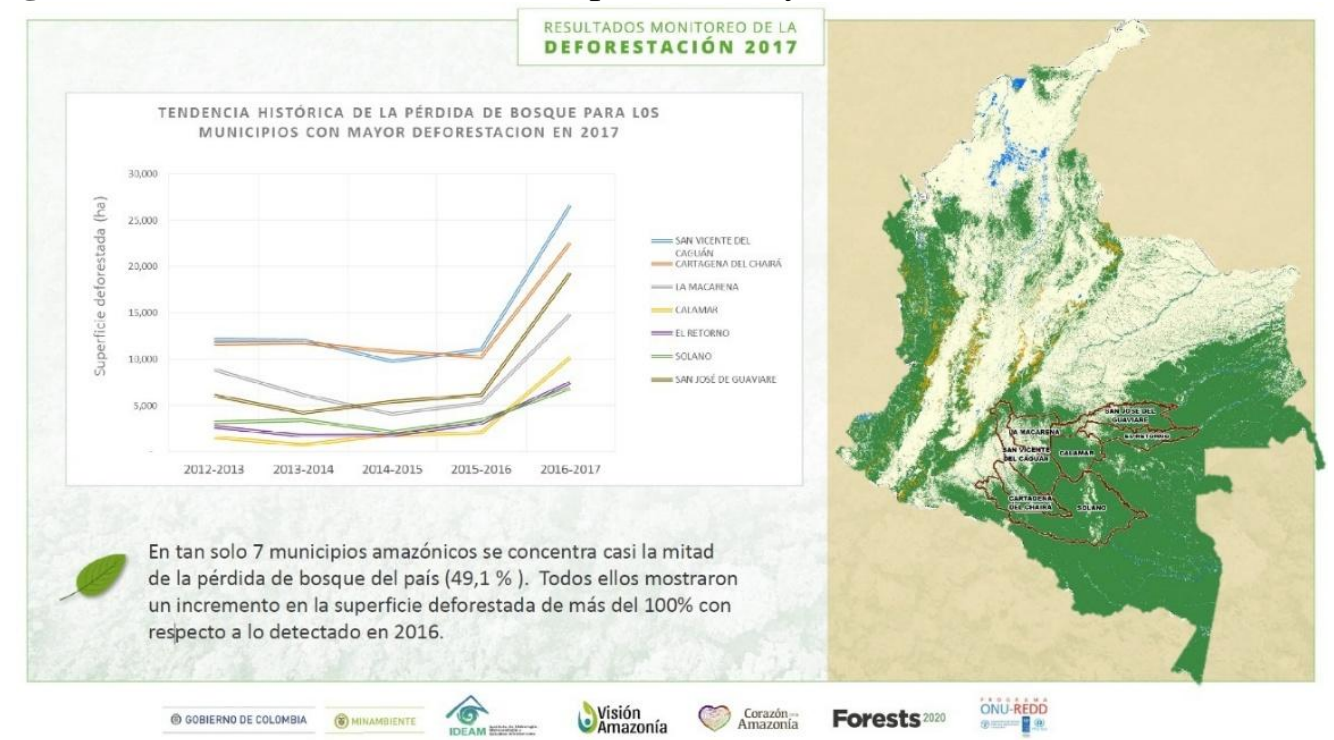

Fuente: Instituto de Hidrología, Meteorología y Estudios Ambientales IDEAM; Ministerio de Ambiente; Gobierno de Colombia, 2017.

Ese evidente aumento en la degradación de la cobertura vegetal, concentrado en una zona bien delimitada, ha obtenido la atención y preocupación pública al tratarse de un espacio de alta importancia ambiental, ya que en él se localizan tres parques nacionales ${ }^{2}$ que hacen parte del Sistema Nacional Ambiental (Parques Tinigua, La Macarena y Chiribiquete), zonas de protección ecológica que están siendo fuertemente impactadas por este fenómeno; además de desenvolver toda una problemática relacionada con el avance de la frontera agrícola en tierras que hacen parte de la Zona de Reserva Forestal de Colombia (Ley 2 de 1959), la cual configura un gran territorio (casi la totalidad de la amazonia colombiana) destinado a un manejo especial, asociado a la preservación de ecosistemas y recursos estratégicos del país.

\section{Antecedentes}

Los municipios identificados en la figura 2, han sido históricamente receptores de campesinos en busca de tierra y de oportunidades económicas relacionadas con dicha dinámica (comúnmente conocidos como “colonos”), quienes han llegado en diferentes momentos de la historia del país, pero con mayor intensidad a mediados del siglo XX, en el

\footnotetext{
${ }^{1}$ Municipios: San Vicente del Caguán, Cartagena del Chairá, La Macarena, Calamar, El Retorno, Solano, San José del Guaviare. Según los datos del IDEAM, la tendencia de concentración de la deforestación en estos municipios se mantiene para el 2018.

2 Áreas protegidas cuya principal vocación es la conservación ambiental.
} 
periodo conocido como la "época de la violencia" (1946-1958), marcada por la intensificación de la violencia de origen político entre los dos principales partidos políticos de la época, los partidos Liberal y Conservador.

Dicha dinámica violenta generó el desplazamiento de importantes cantidades de población campesina, parte de la cual llegó para poblar la frontera noroeste de la Amazonia, especialmente desde el centro y sur de las regiones Andina y Orinoquense, huyendo del conflicto y en busca de nuevas tierras. Debido a que históricamente ésta ha sido una zona apartada y de difícil acceso, con insuficientes vías de comunicación y articulación con el resto del país, se desarrollaron en ella economías de baja intensidad, escala, tecnología y productividad, basadas en la agricultura y la pecuaria campesina de circulación local, así como en el aprovechamiento de productos de la selva como maderables y faunísticos.

Se trata de la configuración de territorios de colonización a partir de las prácticas o territorialidades campesinas, que perfilan trayectorias de transformación espacial, evidenciando el establecimiento de nuevas dinámicas territoriales a partir de la movilización de poblaciones afectadas por los procesos de la violencia política y económica. Ya que en su mayoría se trataba de población campesina pobre, la cual hacía parte de las dinámicas de reproducción de desigualdad de una sociedad específica en un momento histórico particular, esto llevó a su localización en la periferia física, política y económica del proyecto inconcluso del Estado nación colombiano, dinamizando el avance de dicha población en la zona identificada.

Estos territorios cobraron mayor importancia en el contexto nacional a final del siglo $\mathrm{XX}$, a partir de la consolidación de la presencia de las FARC, y de la consecuente intensificación del conflicto armado en ellos. Dicha guerrilla estableció en allí una retaguardia estratégica dada su complejidad geográfica, configurando un nodo estratégico que relaciona y permite el acceso hacia el centro y el sur del país, siguiendo la cordillera de los Andes, así como en dirección hacia las fronteras con Venezuela y Ecuador, siguiendo los cursos de los ríos, principales vías de comunicación en esta parte de Colombia. Por lo tanto, esos territorios de la colonización campesina tomaron un valor diferente en el contexto del conflicto armado, un valor geoestratégico que los tornó un foco de la lucha militar por el control físico y económico, tal como se verá más adelante.

Especial importancia cobra, en este sentido, las fallidas negociaciones de paz entre el gobierno del presidente Andrés Pastrana (1998-2002) y las FARC, pues como parte de este 
proceso se creó lo que fue conocido como "zona de distención", un área desmilitarizada conformada por cinco municipios (los cuales hacen parte de los municipios donde se focaliza la deforestación de la amazonia colombiana), donde las FARC concentraron la mayoría de sus fuerzas militares, como parte de un eventual proceso de desmovilización de las mismas.

En este período, y en medio de las negociaciones, las FARC adelantaron un proceso de fortalecimiento militar y de relacionamiento mayor con el narcotráfico, asumiendo éste como una vía de financiación de sus actividades, las cuales venían siendo sustentadas con base en robos, secuestros, donaciones voluntarias y extorciones (CADENA MONTENEGRO, 2011). Lo anterior marcó la consolidación de la economía de la coca (cultivo, procesamiento para la obtención de pasta base de cocaína y distribución) como una actividad productiva de base en estos territorios, complejizando su situación al sumar una nueva fuente de conflictos por su control, ya que en éstos se llegaron a concentrar la mayoría de los cultivos de coca del país, lo que significó una enorme fuente de recursos económicos para quien consiguiese su dominio.

Dicha dinámica económica ilegal trajo, como consecuencia, que territorios históricamente aislados, tanto en lo físico como en lo social y en lo económico, pasasen a formar parte de nodos en las redes internacionales asociadas al narcotráfico, alcanzando un tipo de globalización por medio de la ilegalidad y de sus lógicas, las cuales responden a las lógicas mismas de circulación del capital, y que consiguieron llevar a ellos flujos de dinero que el Estado nunca consiguió llevar con sus políticas de desarrollo. Es de anotar que dichos flujos estuvieron altamente concentrados, siguiendo las lógicas capitalistas del lucro.

Posterior a las negociaciones mencionadas, las cuales terminaron sin éxito en el 2002, se presentó un aumento en la intensidad del conflicto armado en el área objeto de este artículo (figura 3), relacionado con la llegada al poder del presidente Alvaro Uribe (20022010), quien fortaleció la política de combate contra la insurgencia de izquierda, como las FARC, obligándolas a una retirada estratégica hacia sus zonas de dominio tradicional o más consolidado, entre ellas el límite noroeste la Amazonia, su territorio principal en el pasado reciente del país. 
Figura 3: Dinámica del conflicto armado en Colombia

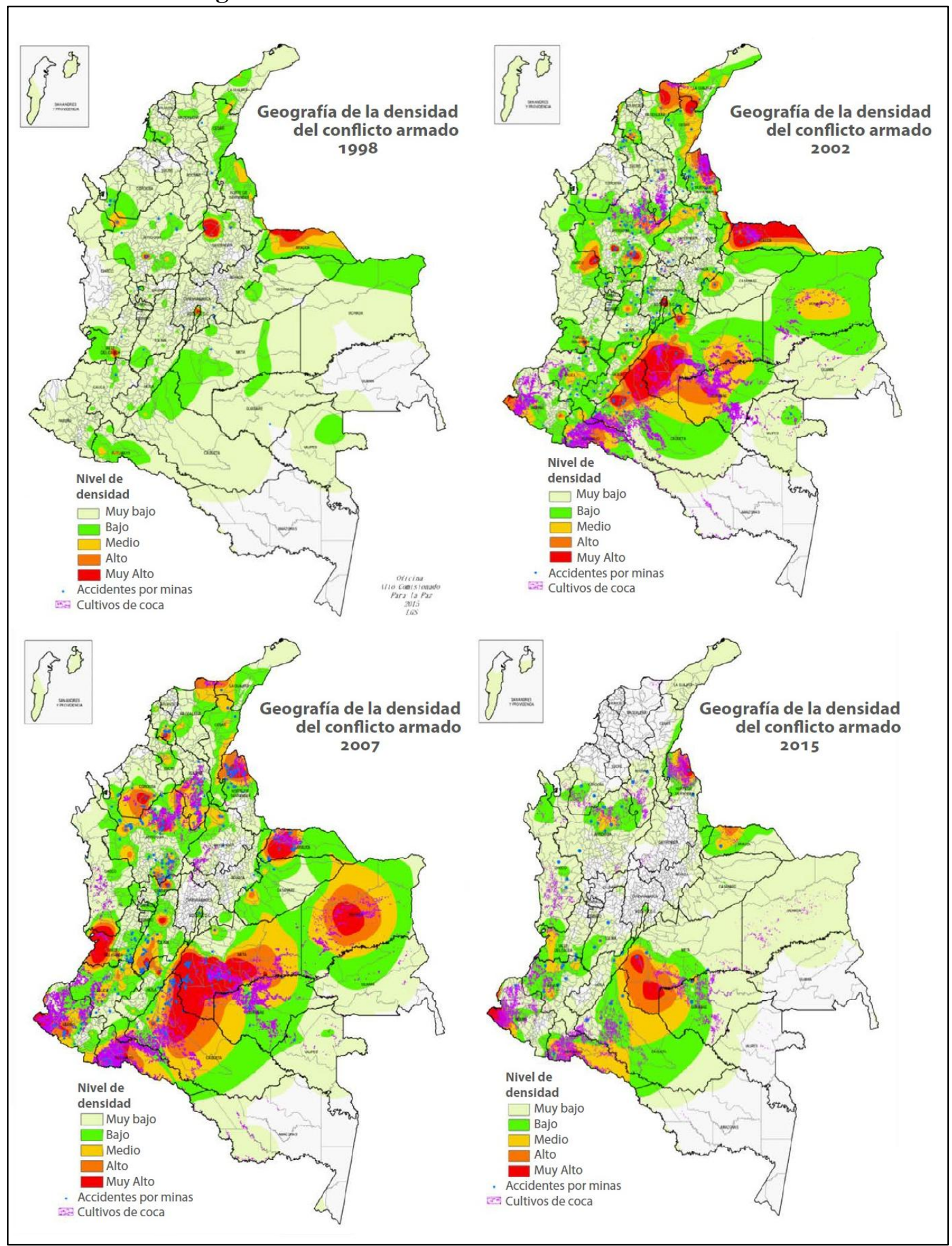

Fuente: SALAS-SALAZAR, 2016, p. 48.

En ese mismo periodo se presentó el fortalecimiento de los grupos armados de derecha conocidos como paramilitares, quienes actuaron en asociación con las fuerzas militares y policiales del Estado, pero que, como señala Salas-Salazar (2016, p. 47), 
rápidamente mudaron su interés del combate contra-insurgente para enfocarse en el control de las rentas del territorio, especialmente de aquellas llegadas del narcotráfico, así como sobre el control del territorio mismo como elemento estratégico de sus acciones militares y económicas, usando para eso la violencia más extrema contra su población.

En esta misma línea, no se puede olvidar el atractivo que configura las rentas del estado, concentradas en los recursos que llegan a los municipios para invertir en sus políticas y programas de desarrollo, los cuales también han sido un botín para grandes organizaciones criminales. Éstas, en asocio con poderes políticos y públicos, y en ocasiones como parte de acuerdos corruptos o como resultado de la coacción, han desviado y administrado dichos recursos para beneficiar intereses particulares, tanto legales como ilegales.

La figura 3 permite evidenciar, fácilmente, la extrapolación de cultivos de coca con la expresión geográfica de la intensidad del conflicto armado a lo largo de tiempo, de la misma manera, aparece con claridad cómo uno de los focos históricos principales de este conflicto, ha sido el área que actualmente concentra la mayoría de la dinámica deforestadora de la Amazonia colombiana y de todo el país.

Es posible coincidir con Saquet cuando afirma que "O território é o conteúdo das formas e relações materiais e imateriais, do movimento, e significa apropriação e dominação, também material e imaterial, em manchas e redes." (SAQUET, 2015, p. 86). En el caso que ocupa este artículo, se hace evidente como se va configurando un territorio cada vez más complejo a partir de la llegada de otros actores y sus intereses, y de la lucha que desencadenan en procura de la hegemonía sobre él; de esta manera, es claro como el territorio sobrepasa su expresión material y deviene una construcción social a partir de la acción de la sociedad misma, así como de las redes que compone y de las diversas escalas en que estas redes se articulan, en conjunción con el contenido histórico y físico del espacio, con sus trayectorias. 


\section{La negociación de paz}

Después de los dos gobiernos de Álvaro Uribe, llegó un impulso fundamental para la negociación de paz entre el Estado y la guerrilla de las FARC en el gobierno de Juan Manuel Santos (2010-2018), producto del cual surgió el "Acuerdo final para la terminación del conflicto y la construcción de una paz estable y duradera" (Gobierno Nacional de Colombia; Fuerzas Armadas Revolucionarias del Pueblo-FARC EP, 2016), firmado entre las partes en 2016. Con éste, la guerrilla de las FARC dejó de existir como organización armada ilegal y pasaron a constituir un partido político.

Este cambio en el papel y el accionar de las FARC, trajo como consecuencia un vacío de poder en los territorios que antes controlaba, mismo que debería ser ocupado por medio de la presencia del Estado, materializada en servicios de salud, justicia, educación, proyectos económicos, de infraestructura y seguridad. Desafortunadamente, por causa de la reconocida ineficiencia estatal y de los poderosos intereses en contra del proceso de paz, dicho fortalecimiento de la presencia y acción estatal no fue alcanzado plenamente, resultando en una exposición del territorio a nuevas luchas por su control por parte de varios actores, entre los que sobresalen las disidencias de las FARC (reductos de esta organización que se mantienen en la lucha armada), la guerrilla del ELN (una de las principales organizaciones guerrilleras de izquierda de Colombia), y los grupos criminales que surgieron a partir de la desmovilización de los antiguos grupos paramilitares. La siguiente figura expresa esas nuevas luchas por el territorio y sus rentas, especialmente aquellas asociadas a la cocaína y sus rutas de tráfico en el noroeste amazónico colombiano. 
Figura 4: Actores armados ilegales y control territorial en Colombia

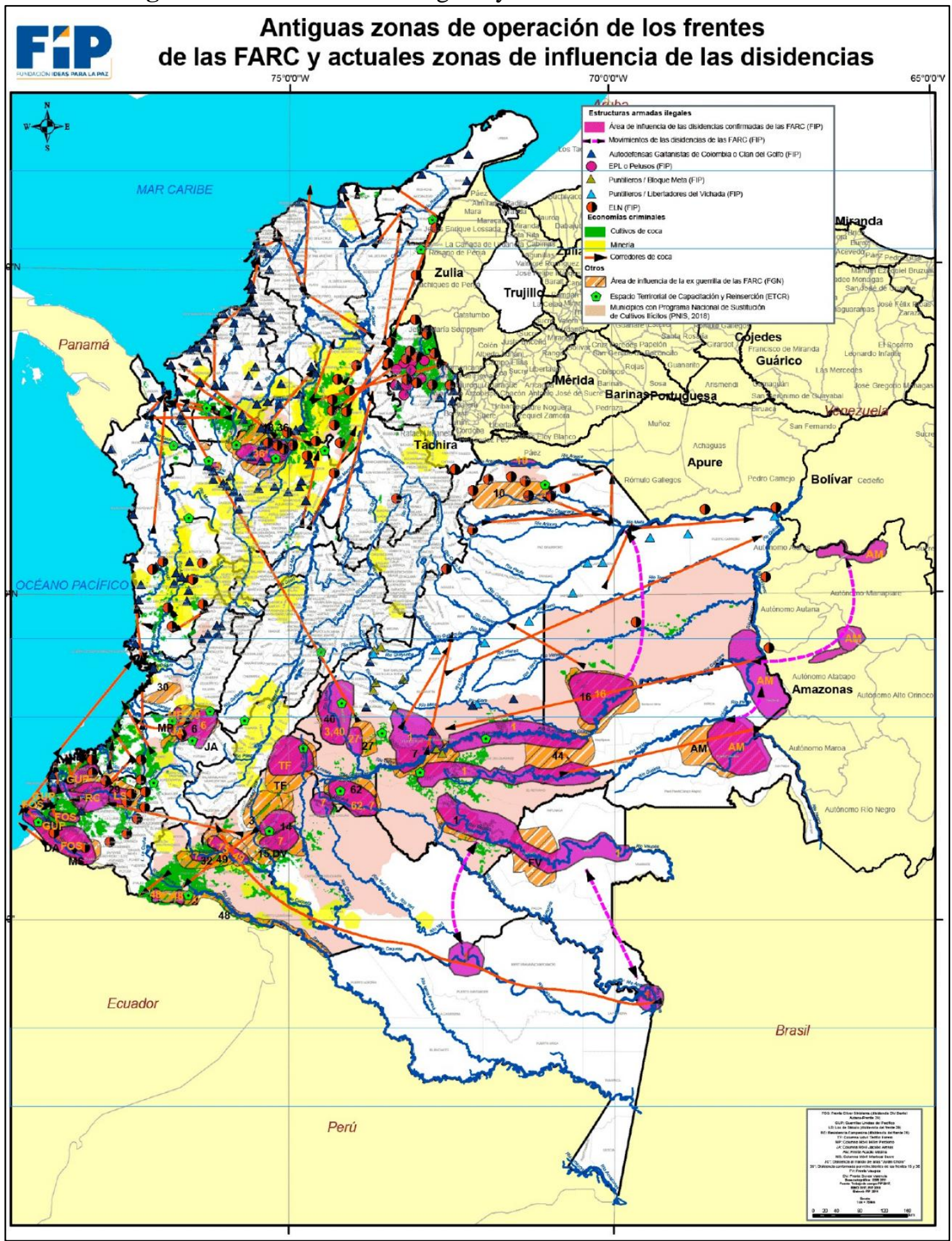

Fuente: ÁLVAREZ; PARDO; CAJIAO, 2018, p. 41.

Para el momento en que está siendo escrito este artículo (segunda mitad de 2019), y bajo un gobierno que se ha posicionado en contra de estos acuerdos (presidente Iván Duque, 2018-2020), el panorama para alcanzar lo que se conoció como "paz territorial” no es bueno, 
lo cual se refleja en la creciente cifra de líderes sociales asesinados (más de 400 desde 2016, según cifras de la Fiscalía General de la Nación, Colombia), entre las que sobresalen líderes campesinos, indígenas y afro-descendientes, quienes reclaman el derecho de recuperar las tierras que fueron expoliadas a lo largo del conflicto político armado, muchas de las cuales terminaron como parte de grandes latifundios, controlados por actores e intereses económicos asociados, en la mayoría de los casos, a grupos armados de derecha (paramilitares).

Ese riesgo, que finalmente terminaron concretando muchos de los territorios dejados del control militar de las FARC después del acuerdo de paz, ya había sido advertido, entre otras, por autoras como Astrid Ulloa y Sergio Coronado (2016), cuando señalaban sobre la importancia de la participación de la sociedad local en la reconstrucción del Estado, y su acción en los territorios que estaban en el centro de los efectos derivados de la negociación de paz. Esto se refiere a la participación social en la creación de un proyecto de desarrollo, en el cual deberían tener cabida diversas expresiones sociales y productivas de lo rural, para evitar la imposición de enfoques y prácticas asociadas a proyectos homogeneizantes y violentos, como es el caso de los proyectos extractivistas por ellos analizados, cruzados por un sesgo hegemónico y utilitarista del territorio y sus recursos.

En un sentido similar se posiciona Wanderley (2009) cuando analiza la ruralidad en el mundo contemporáneo, y la necesidad de alcanzar una nueva concepción de lo rural, más allá de la producción y el agro-negocio, que permita hacerlo parte de un proyecto de desarrollo territorial más incluyente, que valorice el bien estar de los habitantes de esa ruralidad y la permanencia en sus territorios, según sus propias expectativas, necesidades e identidades.

Siguiendo las líneas reflexivas de los autores anteriormente citados, podría afirmarse que lo que sucede en el noroeste de la Amazonia colombiana, en un escenario de pos-acuerdos de paz, es una reedición del histórico abandono del Estado, o su fracaso para traer esos territorios en disputa, e integrarlos a un proyecto democrático e inclusivo de nación. La expresión de esto son las diversas violencias sociales y ambientales descritas hasta aquí.

Pero ¿pude ser esto explicado a partir de la proposición de un Estado colombiano incompetente? ¿O pueden identificarse otras motivaciones y, aún, racionalidades detrás de estos acontecimientos? Si bien la incapacidad para articular la totalidad del territorio nacional a un proyecto de nación ha sido una constante histórica en Colombia, quedarse sólo con esta explicación para intentar vislumbrar las causas y efectos de los procesos territoriales 
analizados, no permite comprender como éstos son impulsados y aprovechados por intereses y actores específicos.

Para el caso en cuestión, los acuerdos de paz en su primer punto, "Hacia un nuevo campo colombiano: Reforma Rural Integral” (Gobierno Nacional de Colombia; Fuerzas Armadas Revolucionarias del Pueblo-FARC EP, 2016), y con el fin de evitar posibles efectos indeseados a partir de la salida de las FARC como actor hegemónico en lo político y en lo económico, y de coadyuvar en la intervención de las causas estructurales del conflicto social colombiano, concibieron la necesidad de una reforma rural integral. Dicha propuesta se apuntala en la necesidad de permitir el desarrollo de diversas expresiones de la ruralidad, garantizando la permanencia de la población campesina más vulnerable y su calidad de vida, y aprovechando esa presencia para implementar propuestas de desarrollo social y ambientalmente sustentables, que permitan cerrar la frontera agrícola y facilitar la conservación de áreas de alta importancia ecológica, cual es el caso de la frontera noroeste de la Amazonia.

Ahora, históricamente y con mayor fuerza después de los acuerdos de paz, Colombia ha sufrido una fuerte influencia de intereses asociados a esferas de poder políticas y económicas, concentradas en promover un proyecto político y económico de desarrollo que beneficie decididamente grandes capitales y sus inversiones, focalizados en su reproducción en las industrias o actividades extractivas, así como en la acumulación de tierra, siguiendo la tendencia de primarización de la económica nacional.

Son esos intereses los principales beneficiarios de la incapacidad, accidental o planeada, del Estado para conseguir hacer presencia efectiva en todo el territorio del país, más allá de su presencia militar y policiva. Sin embargo, el Estado también alcanza "logros" en el marco de su accionar "incompetente", ya que privatiza parcialmente el control del territorio, intentando aprovechar, para ello, el avance del capital en su intento de beneficiarse de nuevas rentas, de dinamizar sectores económicos como el agronegocio y de favorecer aliados en los gobiernos de turno (en todas las escalas administrativas del territorio), con el fin de fortalecerse y alcanzar el esquivo control y pacificación territorial.

Lo anterior parte de reconocer un par de asuntos básicos: el control del territorio es imprescindible para su gobierno efectivo, es un elemento que está en el centro de la naturaleza política y conflictiva del mismo; y de reconocer, por otro lado, que en el actual sistema capitalista globalizado, el poder de definir las trayectorias económicas del espacio, sus usos, 
se configura como un factor clave en el logro de la gobernanza ya mencionada, pues junto con el sistema normativo, determina los derechos de propiedad y aprovechamiento de la tierra.

Es una constante entre las fuentes consultadas para este artículo, el identificar cinco motores que impulsan la deforestación, tales son: la praderización asociada a la penetración de la ganadería extensiva, la expansión de cultivos ilícitos (coca principalmente), la llegada de proyectos de monocultivo de palma aceitera (con insipiente mecanización), la minería (incluida la actividad petrolera), y la expansión de vías carreteables (vías construidas informalmente, fuera de los planes de infraestructuras viales del Estado).

De entre estos motores, el avance de la ganadería extensiva (pocas cabezas de ganado por unidad de tierra) es el principal de ellos, el cual presenta complejas relaciones con acciones de acumulación de tierra y lavado de activos, estableciendo diversas articulaciones con autoridades administrativas municipales y departamentales para lograr la legalización en la tenencia y aprovechamiento de las tierras así conseguidas, asuntos que vienen siendo investigados por las autoridades judiciales colombianas. En esta lógica, el establecimiento de la ganadería no es el principal (por lo menos no el único) objetivo de su expansión, sino la estrategia elegida por los agentes acumuladores para intentar demostrar y legalizar la posesión de nuevas extensiones de tierra, para posteriormente intentar ingresarlas al mercado de tierra asociado al agronegocio.

Dichas acciones de expansión necesitan de la inversión de capitales considerables, los cuales no son dispuestos por actores locales sino por actores externos vinculados a la ganadería, el agronegocio y el mercado de tierras, quienes identificaron en estos territorios la oportunidad de invertir y reproducir dichos capitales, especulando con el valor y el uso del suelo, lo que pasa por transformar su vocación de suelos de protección ambiental, con presencia de agricultura familiar asociada a modos de vida campesinos, a suelos productivos de mayor extensión, impulsando la pérdida de su cobertura vegetal y la expulsión de aquellas formas organizativas y productivas campesinas tradicionales.

Determinar a quién pertenece, quien tiene derechos sobre la tierra, y cómo ésta debe ser usada, ha sido un reto que el Estado colombiano no ha superado, especialmente en sus territorios más periféricos, lo que va de la mano de su muy imperfecta gobernanza en ellos. Permitir el avance de los intereses del capital sobre la tierra, significa facilitar el proceso de normatización estatal de esos territorios, pobremente articulados a las dinámicas centrales de 
la política y la economía, pues tanto el capital, como el Estado, comparten el interés por un territorio controlado y pacificado, que brinde confianza a las intereses externos y estabilidad política, aunque no garantice las condiciones de existencia básicas de sus pobladores ni la calidad del ambiente.

\section{Procesos de reterritorialización, control y redefinición del territorio por el capital}

Expertos como Juan Pablo Ruiz (2019), Economista, Dolors Armenteras (2019), Bióloga, e Carlos Duarte (2016), Antropólogo, coinciden en identificar una lógica y prácticas oscuras atrás de la ocupación de nuevos espacios en territorios de frontera ambiental, pues éstos no terminan bajo el control de campesinos, aunque sean ellos la avanzada de dicha ocupación, sino como parte de grandes latifundios y propiedades asociadas a capitales mayores, o como posesión de actores con gran poder adquisitivo, contrario a la intención de privilegiar la pequeña economía campesina y la preservación ambiental, espíritu de las normas que regulan esta materia (DUARTE, 2016).

En ese sentido, Armenteras (2019) señala como los campesinos del noroeste de la amazonia, son usados como mano de obra barata para dicha expansión, misma que es impulsada por la expectativa de que esas tierras adquirirán un gran valor comercial en el futuro, efectuando así un evidente proceso de despojo, acaparamiento y especulación de tierras. Por su parte Ruiz (2019), además de coincidir con la afirmación precedente, cuestiona directamente ese proceso de acaparamiento relacionándolo con un proyecto político de control territorial, en la búsqueda de transformar las lógicas y las territorialidades imperantes en las épocas del control de las FARC; dicho interés es compartido por diversos actores económicos y políticos, quienes tienen influencia o hacen parte del estado mismo.

Los tres expertos (ARMENTERAS, 2019; DUARTE, 2016; RUIZ, 2019) coinciden en identificar un importante componente de corrupción político-administrativa en todo este proceso, ya que es imprescindible la acción del Estado en los niveles locales, con el fin de legalizar la posesión de tierras apropiadas, y para fortalecer la llegada de nuevos actores y capitales. Es en ese sentido que Ruiz (2019) habla de una política de ocupación del territorio, lo cual es evidente en el caso aquí explorado, pues se trata de una tentativa para redefinirlo en función de los intereses que el capital y el control político tienen sobre él, especialmente por tratarse de un territorio históricamente ubicado en la periferia del Estado. 
Finalmente, todo el proceso es reforzado por la tradición del Estado colombiano de legalizar tierras que hacen parte de la reserva forestal de la nación, a partir de la demostración de posesión y uso que los ocupantes deben hacer, lo que implica una transformación de su uso como tierras de reserva ambiental para usos productivos; lo anterior ha traído como consecuencia la promoción e intensificación de la deforestación, tal como es advertido por Armenteras (2019) y Ruiz (2019).

La intensificación de la deforestación en el noroeste amazónico colombiano, después de la desmovilización de las FARC, la intensificación de la violencia contra poblaciones y líderes campesinos que defienden el derecho a permanecer en sus territorios, la captura y concentración de tierras, y el uso de campesinos para la expansión del dominio de tierras para posibles usos agrícolas y pecuarios, son claras expresiones de lo que Harvey (2007) analizó como el proceso de expansión del capital, que lleva, necesariamente, a un proceso de reterritorialización.

Ese proceso tiene como característica fundamental la creación y aprovechamiento de periodos de crisis, con el fin de expandir las lógicas y el dominio del capital en nuevos territorios y aspectos de la vida social; en el caso aquí analizado, es fácil distinguir como éste cumple con tres de los cuatro elementos fundamentales del proceso, advertidos por Harvey (2007, p. 260): la implantación del capital en nuevas esferas de actividad, como sucede con la especulación de la tierra y el establecimiento de condiciones para la llegada del agronegocio; la promoción de la expansión de la población, en lo cual ha sido fundamental el uso de la población campesina para expandir la frontera productiva y la conquista de tierras; y la expansión geográfica en nuevas regiones, lo que es evidente en la llegada de los intereses por las tierras y por el control político de los municipios focalizados en este artículo, los cuales equivalen a los niveles locales del Estado.

El cuarto elemento es la creación de nuevos deseos y necesidades sociales. Si bien ese no es tan evidente en el caso analizado, permite comprender que el proceso también tiene un importante componente simbólico, representacional, que dispara cambios en las valoraciones y acciones sociales frente a un fenómeno específico; en ese sentido, es interesante entender cómo las ruralidades campesinas, diferente de las que son prometidas por el agronegocio, no parece llevar una mayor preocupación política y pública por su transformación, ya que, como afirma Wanderley (2009), son valoradas como carentes, faltas de desarrollo y poco productivas, lo que justifica su intervención y transformación. Lo 
anterior permite comprender, en parte, por qué se hace evidente un gran interés público por el conflicto ambiental asociado a la deforestación de la amazonia, lo cual no es tan claro con el conflicto social que constituye su base y su fuente.

Siguiendo a Haesbaert (2016), la reterritorialización es comprendida como la resultante de la dinámica responsable por la creación y transformación de los territorios, en sus niveles simbólicos y materiales, que da cuenta del establecimiento de nuevos significados, configuraciones, aprovechamientos y controles del espacio; ésta se encuentra precedida por la desterritorialización, valorada como la irrupción de nuevas trayectorias del espacio, las cuales impulsan o detonan las transformaciones temporalmente concretizadas por la reterritorialización, estableciendo, de esta manera, el ciclo constante del cambio territorial.

Así, el territorio es un estado transitorio del dominio o de la hegemonía sobre el espacio humano, sujeto al incesante juego del conflicto social. El caso expuesto en este artículo, hace evidente cómo la deforestación es tanto una expresión de dicha dinámica, como una técnica para desterritorializar el espacio y las territorialidades campesinas preexistentes, disponiéndolas para una reterritorialización a partir de las lógicas del capital, las cuales harán uso de dichas preexistencias, cooptándolas y, de ser necesario, eliminándolas en su objetivo de configurar un estado de cosas atractivas a la inversión y producción de lucro.

Por otra parte, dicha reterritorialización necesita del establecimiento de una hegemonía simbólica, que permita determinar cómo el espacio es valorado y apropiado, legitimando ese nuevo estado de cosas; es en este punto donde, al parecer, se establece con mayor facilidad un conflicto público por la degradación de la naturaleza, tal como se señaló párrafos atrás, pues tal proyecto choca con las concepciones contemporáneas de conservación, las cuales poco consiguen comprender la importancia de las dinámicas sociales al interior de dicho conflicto.

Lo anterior confirma la proposición señalada por autores como Diegues (2004), quienes afirman que el pensamiento dicotómico propio de la racionalidad occidental, a partir del cual se comprende la naturaleza y la cultura como realidades independientes, se encuentra en el origen de la incapacidad de regular la degradación ambiental, por cuanto esa naturaleza es comprendida como una fuente de recursos o como un espacio estratégico que debe aislarse de la acción de la sociedad, cuando en realidad es la propia presencia de sociedades como las indígenas y campesinas, quienes con mayor éxito pueden garantizar el cuidado de un relativo 
equilibrio ambiental, a partir de relaciones con el medio que no responden a un orden capitalista de explotación y acumulación.

El caso del noroeste de la Amazonia colombiana, permite identificar como el conflicto ambiental de la deforestación, es en realidad un conflicto socioambiental por la reterriotrialización del espacio, disparado por intenciones hegemónicas en lo económico, lo político, lo militar y lo simbólico, que valorizan la tierra como una forma de acumulación y reproducción de dinero, así como de control político-militar. En su intento por imponerse, transforman la sociedad por medio del despojo y mercantilización de sus medios de reproducción (la tierra y las estrategias de producción campesina), y de la cooptación de sus estrategias organizativas e institucionales (los gobiernos municipales), originando un nuevo territorio menos propicio a la diversidad social y más apto para recibir la inversión externa.

\section{Consideraciones finales}

El fenómeno de deforestación en el noroeste amazónico colombiano, más que referir a una coyuntura ambiental, remite a un proceso de transformación territorial (deterritorialización y reterritorialización) en procura del poder para definir sus trayectorias y devenir, cruzado por la historia "reciente" (desde mediados del siglo XX) del conflicto político armado de la nación.

Son territorios que han pasado de ser un frente de colonización campesina, receptor de poblaciones que huían de la violencia política y que buscaban nuevos territorios para asentarse, procurando oportunidades en la periferia de la dinámica de concentración de la tierra y el poder (político y económico) del centro del país; para posteriormente convertirse en un punto fuerte y retaguardia estratégica de las FARC en su apogeo como ejercito insurgente, configurando un nodo de movilidad clave para su accionar; mismo que, con la consolidación del tráfico de cocaína, cobraría un nuevo valor como fuente de renta y financiación, característica que lo pondría en el centro de una violenta confrontación entre las FARC, grupos paramilitares y las fuerzas estatales, por su control y el de dichas rentas.

Más recientemente, después de las negociaciones entre las FARC y el Estado colombiano, dicha pugna se ha reeditado e incluso intensificado, ya que la salida de las FARC como actor hegemónico, y la incapacidad del Estado para asumir ese vacio, resultaron en la apertura del territorio para el embate de antiguos y nuevos actores interesados en su control; es así como continúan los enfrentamientos entre disidencias de las FARC, el ELN, y grupos 
criminales derivados de antiguos grupos paramilitares, relacionados con carteles del narcotráfico, por el control delas rentas de la producción de cocaína.

Por otra parte, la mencionada salida de las FARC como actor militar y político hegemónico, ha abierto la posibilidad para el avance de un proyecto territorial (político y económico) diferente, que pretende llevar estos territorios a los circuitos de inversión del agronegocio y el mercado de tierras, visando establecer un control que permita alcanzar una mayor gobernabilidad, proyecto al cual se articula el Estado en sus diferentes niveles territoriales, y que impulsa la concentración de tierras y la transformación del uso del suelo, siendo la deforestación una estrategia básica en dicho proceso.

Por lo tanto, la aceleración de la deforestación de la Amazonia colombiana es el resultado de los cambios en el poder hegemónico territorial, acontecidos a partir de la salida de las FARC como organización militar, con dominio político en los territorios más impactados por este fenómeno en la actualidad; ese conflicto socioambiental tiene su explicación en los procesos de reterritorialización que vienen aconteciendo, los cuales están cruzados por las trayectorias del conflicto político armado del país, y que tienen como resultado la configuración de múltiples violencias ambientales y sociales, donde la población campesina, históricamente más vulnerable y afectada por el conflicto, queda en el centro del proceso como instrumento y como víctima.

Al mismo tiempo, la deforestación y el uso de la población campesina para esta actividad, hacen parte de una técnica de gobierno y control de estos territorios, realizada por diversos actores que establecen múltiples relaciones de conflicto y asociación, con el fin de consolidar y ampliar un espacio que, en un futuro cercano, sea atractivo para la inversión de capital bajo el paradigma del agronegocio. Paralelamente el acaparamiento de tierras, siendo él mismo una forma de producción y reproducción del capital (legal e ilegal), es también una vía de control estratégico y político del territorio, el cual responde a la lógica que señala a los grandes poseedores de tierra como influenciadores clave de sus trayectorias y procesos, consolidando así una suerte de privatización del control territorial del Estado.

\section{Agradecimientos}

Agradecimientos a la Coordenação de Aperfeiçoamento de Pessoal de Nível Superior - CAPES, Brasil, por la financiación de los estudios de doctorado del autor de este artículo, lo cual hizo posible su elaboración. 


\section{REFERENCIAS}

ÁLVAREZ VANEGAS, Eduardo; PARDO CALDERÓN, Daniel; CAJIAO VÉLEZ, Andrés. Trayectorias y dinámicas territoriales de las disidencias de las FARC. Bogotá: Fundación Ideas para la Paz FIP, 2018.

ARMENTERAS, Dolors. Luego del acuerdo con las Farc, los conflictos ambientales cambiaron pero no desaparecieron. Semana Sostenible, Bogotá, 4 de mayo de 2019. Entrevista concedida a Antonio Paz/MongabayLatam. Disponible en: https://sostenibilidad.semana.com/medio-ambiente/articulo/luego-del-acuerdo-con-lasfarc-los-conflictos-ambientales-cambiaron-pero-no-desaparecieron/44075. Acceso en: 31 julio 2019.

CADENA MONTENEGRO, José; La Geografía y el poder. Territorialización del poder en Colombia: El caso FARC - De Marquetalia al Caguán -. Perspectiva Geográfica, Universidad Pedagógica y Tecnológica de Colombia, Bogotá n. 8, p. 7-30, 2011. Disponible en:

https://revistas.uptc.edu.co/revistas/index.php/perspectiva/article/view/1676. Acceso en: 28 julio 2019.

DIEGUES, Antonio C. O mito moderno da natureza intocada. 5. ed. São Paulo: Hucitec/USP, 2004.

DUARTE, Carlos. Los desafíos campesinos de las zonas de reserva forestal. La Silla Llena, Bogotá, 19 de agosto de 2016. Disponible en: https://lasillavacia.com/sillallena/red-rural/historia/los-desafios-de-las-zonas-de-reserva-forestal-57588. Acceso en: 30 julio 2019.

Gobierno Nacional de Colombia; Fuerzas Armadas Revolucionarias del Pueblo-FARC EP. Acuerdo final para la terminación del conflicto y la construcción de una paz estable y duradera. Bogotá: 2016.

HARVEY, David. Espacios del capital: hacia una geografía crítica. Madrid: Akal, 2007.

HAESBAERT, Rogério. O Mito da Desterritorialização: do "Fim dos Territórios" à Multiterritorialidade. Rio de Janeiro: Bertrand Brasil, 2016.

Instituto de Hidrología, Meteorología y Estudios Ambientales IDEAM; Ministerio de Ambiente; Gobierno de Colombia. Resultados Monitoreo de la Deforestación 2017. Bogotá: 2018. Disponible en:

http://documentacion.ideam.gov.co/openbiblio/bvirtual/023835/Resultados_Monitoreo_ Deforestacion_2017.pdf. Acceso en: 29 julio 2019.

FINER M, Mamani N. Deforestación en la Amazonía Colombiana - 2020. MAAP \#120. Monitoring of the Andean Amazon Project, 2020. Disponible en: https://maaproject.org/2020/colombia-2020/. Acceso en: 20 julio 2020.

RAFFESTIN, Claude. Por uma Geografia do Poder. São Paulo: Editora Ática. 1993. 
RUIZ, Juan Pablo. Deforestación: ¿una política de ocupación del territorio? Semana Sostenible, Bogotá, 2 de abril de 2019. Entrevista concedida a Semana Sostenible. Disponible en: https://sostenibilidad.semana.com/medioambiente/articulo/deforestacion-una-politica-de-ocupacion-del-territorio/43647. Acceso en: 31 julio 2019.

SALAS-SALAZAR, Conflicto armado y configuración territorial: elementos para la consolidación de la paz en Colombia. Bitácora Urbano Territorial, Universidad Nacional de Colombia, Bogotá, n. 26, p. 45-57, 2016. Disponible en: http://dx.doi.org/10.15446/bitacora.v26n2.57605. Acceso en: 27 julio 2019.

SANTOS, Milton. La naturaleza del espacio: técnica y tiempo. Razón y emoción. Barcelona: Ariel, 2002.

SAQUET, Marcos. Abordagens e concepções de territorio. São Paulo: Outras Expressões, 2015.

SAQUET, Marcos. Por uma abordagem territorial. In: SAQUET, Marcos; SPOSITO, Eliseu (Org.). Territórios e territorialidades. Teorias, processos e conflitos. $2^{\mathrm{a}} \mathrm{ed}$. Rio de Janeiro: Consequência Editora, 2015. p. 69-89.

ULLOA, Astrid; CORONADO, Sergio. Territorios, Estado, actores sociales, derechos y conflictos socioambientales en contextos extractivistas: aportes para el posacuerdo. In: ULLOA, Astrid; CORONADO, Sergio (Ed). Extractivismos y posconflicto en Colombia: retos para la paz territorial. Bogotá: Universidad Nacional de Colombia, 2016. p. 23-58.

WANDERLEY, Maria de Nazareth Baudel. O mundo rural como um espaço de vida: reflexões sobre a propriedade da terra, agricultura familiar e ruralidade. Porto Alegre: Editora da UFRGS, 2009. 